\title{
Signal transduction, cell division, differentiation and development: Towards unifying mechanisms for pattern formation in plants
}

\author{
Marcelo Carnier Dornelas
}

Escola Superior de Agricultura Luiz de Queiroz - USP, Departamento de Ciências Florestais, Av. Pádua Dias, 11, CP 9, CEP 13418900 Piracicaba, SP.E-mail:mcdornel@esalq.usp.br

Received:18/11/2002, Accepted: 27/12/2002

The elaboration of plant form and function depends on the ability of a plant cell to divide and differentiate. The decisions of individual cells to enter the cell cycle, maintain proliferation competence, become quiescent, expand, differentiate, or die depend on cell-to-cell communication and on the perception of various signals. These signals can include hormones, nutrients, light, temperature, and internal positional and developmental cues. In recent years, progress has been made in understanding the molecular control of plant pattern formation, especially in the model plant Arabidopsis thaliana. Furthermore, specific genes have been found that are necessary for normal pattern formation and the control of the rates of cell division and differentiation. Cloning of these genes is revealing the molecular basis of plant pattern formation and the key players on plant signal transduction systems.

Key words: cell differentiation, developmental genetics, transduction pathways.

Transdução de sinal, divisão celular, diferenciação e desenvolvimento: mecanismos unificadores para padrão de formação em plantas: A elaboração da forma e função das plantas depende da habilidade de a célula vegetal dividir-se e diferenciar-se. As decisões tomadas por células individuais de entrar em divisão, manter a proliferação, tornarem-se quiescentes, expandir, diferenciar ou morrer, dependem da comunicação intercelular e da percepção de vários sinais. Esses podem incluir hormônios, nutrientes, luz, temperatura e/ou outros indicadores de posicionamento interno. Recentemente, têm sido alcançados progressos na compreensão do controle molecular da formação de padrões de desenvolvimento em plantas, especialmente na planta-modelo Arabidopsis thaliana. Adicionalmente, genes específicos têm sido identificados como necessários para a formação de padrões normais e para o controle das taxas de divisão e diferenciação. A clonagem de tais genes tem revelado a base molecular da formação de padrão em plantas e identificado os principais elementos nos sistemas de transdução em vegetais.

Palavras-chave: desenvolvimento genético, diferenciação celular, vias de transdução.

\section{INTRODUCTION}

Pattern formation is the process by which the spatial aspect of cellular differentiation is organized (Wolpert, 1996). The two central questions concerning the establishment of pattern and form during the development of higher eukaryotes, and thus in plants, are: 1 . how is the genetic information translated in a reliable manner to yield a specific and complex multicellular organism and 2. how do organisms, that do not look at all like each other, develop by using a same basic set of molecules and often in much the same way (Wilson et al., 1997; Gubb, 1998). Take for example a leaf, how do vascular tissue and epidermis differentiate in just the right place during the late development of the organ? Thus, pattern formation focuses less on the cell differentiation itself rather than on the spatial organization of differentiated cells. After all, the main difference of an Arabidopsis and a maize leaf relies less on the differences in the differentiation of vascular tissue and epidermis than on their spatial arrangement and differential growth. In plants, the spatial organization of cells is largely the result of controlled cell divisions (Meyerowitz, 1997; Bowman and Eshed, 2000). Cell-cell 
communication, based on signal transduction pathways, mediates the necessary complexity for refined regulation of a cell's response to its environment.

\section{High fidelity and minimum information}

During the twentieth century, one of the core problems in developmental biology has been to understand how morphogenetic information is encoded. A mature plant is clearly more complex than its embryo. The developmental program, however, passes through an "information bottleneck" carrying a single copy of DNA. This characterizes the theoretical problem of the "Turing machine ". Early in the twentieth century, Turing (1936) considered the properties of a machine that could read information encoded on a tape. The information to build the machine itself could indeed be encoded, but it was not possible for the tape to encode a blueprint of the machine including the copy of the tape itself. During biological replication, the problem of the "Turing machine" is avoided as the fertilized egg inherits both a copy of the genetic information and a highly organized cellular structure (Gubb, 1998).

The increase in complexity during development, however, cannot simply be explained as a single consequence of re-iterating the "hard-copy" information encoded in the DNA with each successive cell division. Instead, developmental information is likely to be generated by the sequential interactions between cells. Given that for every generation the starting point of the initial stage of development is a single cell, most of the above interactions will occur between neighbouring cells. Such localized interactions are likely to be maintained even when the behaviour of large numbers of cells is integrated within a developing organism. The study of pattern formation during embryo development separated from the study of pattern formation during post-embryonic plant development, resulting from meristem functioning, is merely an academic artefact. Probably the same molecular events, perhaps even the same molecules, are involved. During evolution many of the key gene products that control conserved cellular processes, regulated precisely in single cells such as yeasts, have become secondarily incorporated into morphogenetic pathways (Wilson et al., 1997; Gubb, 1998). As a corollary of this view, it has been suggested that plant cells with the same developmental fate have the same positional information (Bowman and Eshed,
2000). Provided that the growth of embryos and meristems is controlled to such an extent that regions or compartments containing similar cells have the correct size and shape, the specification of individual cell fates is not compulsory. This would greatly reduce the information requirement. It is only within fine-scale fields, such as the megaspore mother cell in an ovule or at the boundary between floral organs, that additional information is necessary. Within these fields, cells adopt differential fates with respect to their immediate neighbours. At no stage during development is there a precise genetic description of the adult plant.

\section{Compartments and allocation of regional fate: A heritage from Drosophila}

Key advances in developmental genetics in the later half of the twentieth century have been the identification of the fate-determining homeotic (Lewis, 1978) and the segmentation genes (Nüsslein-Volhard and Wiescaus, 1980) in Drosophila. The study of compartment-specific phenotypes and several homeotic mutants formed the basis of the selector gene hypothesis (Garcia-Bellido, 1996). This theory postulates that developmental pathways are controlled within progressively smaller regions by the sequential activation of territorial genes. The latter theory has been confirmed in plants by recent genetic and molecular studies (Bowman and Eshed, 2000; Dornelas et al., 2000; Honma and Goto, 2001). According to this model, groups of cells become isolated into modular entities (i.e. developmental compartments) associated with the specific expression of "territorial" (selector) genes in all the cells of a module. These groups of cells may be polyclonal in origin but establish identical identities through cell-cell communication. Cell proliferation within modules is indeterminate, but the cell identity cannot cross module borders. Later these modules correspond to organs or subsegmental entities in the mature organism. Hence, compartment or domain borders become major organizational entities. Exchange of signals from either side of these borders drive differential gene activity. Thus, the territorial specification of cells by selector genes is implicated in cell behaviour and hence in developmental operations. Following further cell proliferation, new subdivisions of territories appear, each specified by new selector genes. In this way, the genetic specification of modules results from transient associations between genes and proteins in combinatorial devices operating in the same 
cells (Honma and Goto, 2001). This patterning system may generate complex structures starting from quite homogenous groups of cells and requires few genetic elements and thus, minimum information. How general is this mechanism? Is this hypothesis relevant to all organisms? Many other theories explaining tissue patterning based on the "selector" hypothesis have been reported such as the " epigenetic selection" (Sachs, 1988) and the "chance-selection" models (Kupiec, 1997). The later includes stabilization of stochastic gene expression by protein kinases and phosphatases (Kupiec, 1997).

\section{Protein kinases and signal transduction in plant development}

Protein kinases function in signalling pathways important for proper pattern formation and cell fate determination during the development of many organisms. One of the most studied transduction systems is the Drosophila wingless signalling pathway, where the SHAGGY protein kinase is a key component (Siegfried et al., 1990). It is a homologue of the mammalian GLYCOGEN SYNTHASE KINASE-3 (GSK-3; Woodgett, 1990). SHAGGY homologues have been cloned from many other organisms and have been shown to be involved in signal transduction pathways that control patterning and cell fate determination. Signal transduction pathway elements have been conserved between animals and plants during evolution (Wilson et al., 1997). Consistent with this idea, plant homologues of SGG/GSK-3 have been described for Arabidopsis (Dornelas et al., 1997; 1998; 1999; 2000). Cues about the biological role of the plant homologues of SGG/GSK-3 have been obtained recently (Dornelas et al., 2000) and their implication in the establishment of pattern formation and specification of cell fates has apparently been conserved during evolution.

Another plant protein kinase involved in development is the receptor-like kinase CLAVATA1 (CLV1; Clark et al., 1997). It has been proposed that CLV1 is responsible for maintaining the proper balance of undifferentiated cells and cells dedicated to organ formation in the shoot meristem. The clv1 mutant shows enlarged shoot, floral meristems and excess floral organs (Clark et al., 1993). The current model of CLV1 signalling proposes that the CLV1 receptor recognizes an extracellular ligand, multimerizes and trans-autophosphorylates. Upon phosphorylation of the cytoplasmic domain, other proteins would participate to transduce the signal resulting in a change in cell division response (Williams, 1997). A protein phosphatase, named KAPP, has been shown to bind to the CLV1 protein in vitro (Williams, 1997). Genetic interaction studies have also implicated the CLAVATA3 (CLV3; Clark et al., 1995) gene product in the CLV1 pathway, suggesting that $C L V 3$ may encode a ligand for the $C L V 1$ receptor.

Thus like animals, plants also make use of signalling pathways involving phosphorylation events to transduce signals that mediate the control of cell division and pattern formation.

\section{Sequential pattern formation}

The creation of pattern by successive compartimentalization of cells that obey more and more precise developmental pathways seems to be the preferred hypothesis to explain regional cell fate allocation in Drosophila (Garcia-Bellido, 1996). In plants, the embryonic development has been viewed conceptually as a series of partitioning events that sequester increasingly more specialized regions (Laux and Jürgens, 1997). Genetic and molecular studies have defined a network of genes that control floral meristem identity and floral organ development in the model plants Arabidopsis thaliana, Antirrhinum majus and other species (Coen and Meyerowitz, 1991; Weigel and Meyerowitz, 1994; Sessions et al., 1998). Three general categories of genes have been shown to act sequentially to control the development of floral primordia. First, floral meristem identity genes act early in the process to specify floral identity rather than shoot identity. Second, cadastral genes act to spatially regulate the extent of the expression pattern of the floral organ identity genes. Third, the homeotic or floral organ identity genes act to specify the organ type into which an organ primordium develops, following the "ABC model " (Sessions et al., 1998; Dornelas, 2000). The pattern of flower development is controlled by the floral meristem, which contains dividing cells that will give rise to the different organ systems of the flower.

In Arabidopsis and many higher plants, the floral meristem is derived from a shoot meristem that has been converted into an inflorescence meristem. The shoot apical meristem (SAM) is itself a highly organized structure that makes use of cell-cell communication and positional information to be maintained (see Laufs et al., 1998). Late in flower development, male and female reproductive organs are formed. 
The ovule is the principal female reproductive organ in higher plants and is a patterned structure formed by at least three independent domains (Gasser et al., 1998). Patterning of the ovule primordium proceeds in a sequential fashion during primordium development. In the model suggested by Schneitz et al. (1998), the three domains are established from the distal end downwards along a proximal-distal axis, where pattern elements are established progressively.

Thus, many aspects of plant patterning seem to obey a basic principle where cells are submitted to successive compartimentalization and obey more and more precise developmental pathways. This is highly reminiscent of the mechanism proposed for fate allocation in Drosophila (Garcia-Bellido, 1996).

\section{Cell polarity and cell fate decisions in plants}

A critical element in generating cellular diversity during development is the polarized flow of information between cells. Such communication requires the cells themselves to be polarized. The first indication of apicalbasal polarization in a number of higher plants is the asymmetrical division of the zygote (Jürgens et al., 1997). The apical-basal axis of the embryo is normally aligned according to the chalaza-micropyle axis of the ovule, suggesting an orienting influence of the surrounding maternal tissue. The embryo sac, egg cell and zygote appear polarized in many higher plant species (Willemse and Van Went, 1984). However, the obtainment of somatic embryos in vitro demonstrates that apical-basal polarity can be established without maternal information. Additionally, maize zygotes formed by in vitro fusion of isolated egg and sperm cells acquire polarity before undergoing an asymmetric division (Breton et al., 1995). In the brown alga Fucus, the free-living zygote becomes polarized in response to external cues, such as light (Kropf, 1997). Nevertheless, the strict correlation between the orientation of the apical-basal axis of the embryo and the structure of the ovule indicate that an information flow between maternal and embryonic tissues may exist. Another source of positional information for the developing embryo include the endosperm and the suspensor cells (Laux and Jürgens, 1997). The acquisition of different cell fates after the first division of the zygote is reflected by the expression of the ARABIDOPSIS THALIANA MERISTEM LAYER1 (ATML1) gene in the apical, but not in the basal cell (Lu et al., 1996). This homeobox gene continues to be expressed in all the derivatives of the apical cell until the octant stage. At this point, another polarized structure is formed, namely the epidermis. Like cells of the animal epithelia, plant epidermis cells have an outer (apical) and an inner (basolateral) surface. The embryo epidermis (protoderm) is formed by tangential divisions of the eight cells derived from the apical daughter cell of the zygote. Prior to their divisions, the eight cells express the ATML1 gene. Following cell division, ATML1 expression is maintained in the epidermal precursors but not in the inner cells $(\mathrm{Lu}$ et al., 1996).

\section{Cell-cell interactions and the definition of boundaries by controlling cell division}

A particularly good example of stereotypical cell divisions is provided by the root apical meristem (Doerner, 1995; Martin et al., 2001), making it a suitable system for testing the respective roles of cell-cell interactions and cell lineage in patterning. In order to examine how cells acquire identity progressively during their journey through the

Arabidopsis root meristem, van den Berg et al. (1995) investigated the consequences of killing specific cells with a laser. When the central cells of the meristem in the root cap were ablated, their debris was displaced apically by the dividing vascular cells. The latter cells, after displacement, rapidly lost expression of a vascular-specific marker and started to express a root-cap specific marker instead, indicating that they had changed fate in response to their new position within the root (van den Berg et al., 1995). This evidence of developmental plasticity is remarkable, because the lineages that generate the vascular and the root cap cells diverge as far back as the first zygotic division (Martin et al., 2001). Similarly, the ablation of cortical cell initials enabled pericycle cells to expand into the cortical cell spaces, where they behaved like cortex cells and expressed cortex marker genes. These results suggest that patterning and differentiation in root tissues are governed by cell-cell communication mechanisms.

Having found that plants use inductive interactions to control their development, the next question is: what is the nature of the molecules that mediate cell-cell interactions during plant development? Sakai and colleagues (Sakai et al., 1995) have started to provide some answers, through the cloning of the SUPERMAN (SUP) gene. The gene was originally identified by loss-offunction 
sup mutations that caused the appearance of extra stamens at the expense of carpels in Arabidopsis flowers, suggesting that the SUP wild-type protein delimits the expression domains of organ identity genes, such as APETALA3 (AP3) and PISTILLATA (PI), which promote stamen development (Weigel and Meyerowitz, 1994). However, AP3 and PI expression precede that of $S U P$, and in fact the AP 3 and PI products are positive regulators of $S U P$ expression (Sessions et al., 1998). Since phenotypic and genetic criteria showed that the $A P 3$ and $P I$ expression domains are expanded in sup mutants, the wild-type SUP protein must evidently affect the number of $A P 3 / P I$-expressing cells. How this mechanism works can be deduced from the location of cells expressing SUP. The latter cells were shown to occupy a subset of the $A P 3 / P I$-expressing domain, namely at the boundary between the third and the fourth whorls (Sessions et al., 1998). Thus, it appears that SUP does not act by repressing AP3/PI expression in cells of the fourth-whorl region, but rather by preventing the proliferation of $A P 3 / P I$-expressing cells, at the boundary between the third and fourth whorls. To explain the sup phenotype (i.e. the expansion of $A P 3 / P I$-expressing cells at the expense of fourth-whorl cells) Sakai et al. (1995) additionally postulated that the SUP protein interferes with a signal that emanates from the cells of the third-whorl boundary and causes reduced proliferation of the fourth whorl. As the SUP protein is a transcription factor, other signal transduction pathway elements must be involved. The finding of a special population of boundary cells, possibly involved in providing neighbouring cells with proliferative signals, is reminiscent of the boundary cells postulated by Vincent et al. (1995) on the basis of their lineage studies of snapdragon flowers and the studies on tissue boundary formation in Drosophila (Skaer, 1998)

\section{Evolution of pattern formation: A matter of tinkering ?}

The origin and early diversification of land plants mark an interval of unparalleled innovation in the history of plant life. From a simple plant body consisting of only a few cells, land plants (e.g. liverworts, hornworts, mosses and vascular plants) evolved an elaborate two-phase life cycle and an extraordinary array of complex organs and tissue systems. Specialized sexual organs (gametangia), stems with an intricate fluid transport mechanism (vascular tissue), epidermal structures for respiratory gas exchange (stomata), leaves and roots of various kinds, diverse sporebearing organs (sporangia), seeds and the tree habit had all evolved by the end of the Devonian period (Kenrick and Crane, 1997). These and other innovations led to the initial assembly of plant-dominated terrestrial ecosystems, and had a great effect on the global environment.

However, the most widely heralded result to emerge from molecular techniques applied to detailed studies on the evolution of developmental programmes is that much of the molecular machinery underlying development is conserved (Wilson et al., 1997; Baum, 1998; Dornelas et al., $1997 ; 1998 ; 1999 ; 2000)$. More particularly the conservation of the biochemical functions of homologous proteins (e.g. protein kinases), has been established even from phylogenetically distant taxa (Dornelas et al., 1999; 2000). This landmark of modern biology presents us with an apparent paradox namely that organisms, very different in appearance, develop by using much the same basic set of molecules and often in much the same way (Kimble, 1994). If we limit our spectra to higher plants, where genomic syntheny is observed either among monocots (Goff et al., 2002; Yu, 2002) or dicots (Tagi, 2000), how then are we expected to explain the remarkable diversity of forms?

According to the established neo-Darwinian view of the evolutionary process, large phenotypic differences are based on numerous gene substitutions, each having individually only a relatively small effect on the phenotype (see review by Palopoli and Patel, 1996). However, many examples do exist in the literature concerning plant development that seem to conflict with this view. One good example is the TEOSINTE BRANCHED1 (TB1) gene, which is responsible for apical dominance, one of the main differences between maize and its ancestral relative (Doebley et al., 1997). Whereas teosinte plants bear many long axillary branches that are tipped by male inflorescences (i.e. tassels), maize plants have fewer, short axillary branches tipped by female ears. A single gene, TB1, controls this transition (Doebley et al., 1997). Another example is the control of flower symmetry. Several mutations have been described in Antirrhinum, a species with asymmetric flowers that reduce or eliminate asymmetry along the dorso-ventral axis (Coen et al., 1995). A mutation in the single Antirrhinum gene CYCLOIDEA $(C Y C)$ gives a radially symmetrical flower phenotype (Luo et al., 1995). A mutation in a single homeotic gene such as APETALA2, or AGAMOUS, both having ortologues already identified in several plant species, could change flower morphology and fertility drastically, events that could initiate a speciation process (Coen, 1991). 
On the basis of this paradigm, we might expect that numerous, subtle alterations or one-step changes in the action of similar collections of genes, when compounded over multiple levels of regulation and occurring in increasingly divergent cellular contexts, result in multiple changes that will lead to the observed phenotypic diversity of plant species.

The evolutionary process of successive gene recruitments for new developmental functions (Duboule and Wilkins, 1998) is an obligatory consequence of the existence of a shared set of plant (or even eukaryotic) genes. Such processes produce a picture of gene function that is at odds with the prevalent assumption that many individual genes exist "for" unique developmental functions. The conventional view of single, dedicated gene function is not only erroneous in itself but subtly distorts thinking about the nature of the evolutionary process. The transitions from gradual to discontinuous rates of evolutionary change are an inevitable consequence of the multiple use of genes through evolutionary tinkering given appropriate selective pressures. This evolutionary view is termed "transitionism" (Duboule and Wilkins, 1998) and seems to reflect well the transformations observed during the evolution of most, if not all, plant gene families.

Paleontologists have been able to delineate a punctuated equilibrium (Gould and Eldredge, 1993) or sudden bursts of morphological change in the fossil record, such as the Cambrian explosion of animal phyla or the Devonian radiation of land plants (Kenrick and Crane, 1997). These periods of dynamic change may have been produced in part by discontinuous processes at the molecular level, including gene duplication and divergence of several genes in a functional pathway. A study of plant gene family evolution may help to illuminate simple and fundamental patterns in the history of actual plant species. As an example, a reconstruction of the history of the MADS-box gene subfamilies based on the taxonomic distribution of contemporary subfamily members revealed that each subfamily comprises highly conserved putative orthologues and recent paralogues (Theissen et al., 2000). In general, subfamily members tend to share highly similar sequences, expression patterns and related functions. Nevertheless, these gene subfamilies may have been essential prerequisites for the establishment of certain reproductive structures in higher plants (Theissen et al., 2000). Phylogenetic trees indicate that after the establishment of different gene subfamilies, additional sequence duplications led to a further increase in the number of MADS-box genes. However, several molecular mechanisms of MADS-box diversification were used to a quite different extent during animal and plant evolution. Known plant MADS-domain sequences diverged much faster then those of animals, and gene duplication and sequence diversification were extensively used for the creation of novel genes during plant evolution, resulting in a relatively large number of interacting genes (Theissen et al., 2000)

These observations demonstrate that in plant evolution, increased combinatorial interactions of gene family products correlates with the evolution of increasingly complex body plans.

\section{Conclusion and Perspectives}

Evidence has accumulated indicating that pattern formation in plants obeys developmental rules postulated by evolutionary conserved transduction pathways. What is then the molecular nature of the signals transmitted between plant cells? Unfortunately the traditional study of developmental gene mutants and their relationship with each other has been of little help in answering this question as most of them encode transcription factors. Secreted molecules that mediate the non-cell-autonomous effects of transcription factors in animals have not been discovered in plants. Nevertheless, the presence of secreted molecules regulating plant development has been directly demonstrated (Rojo et al., 2002), The classical plant hormones, such as auxin and ethylene, must also be included on the list of potential signals. Signal transduction systems often are inappropriately portrayed as simple linear chains of cause and effect. This is in part because effective conceptualization of what goes on when a cell perceives a signal is difficult due to our inability to put together all the experimental information in any meaningful way. The familiar genetic system, where a gene gives a product, which gives a phenotype, is only truly applicable to the very limited number of phenotypic characters thought to be specified by single genes. By contrast signal transduction systems involve interacting genes and gene products that are integrated with networks that transduce a host of internal and external signals. This integration creates an enormously complex but flexible unstable regulatory network interposed between the unitary genetic 
elements and the phenotype. Then what creates the specificity of response to particular signals? The answer is holistic: It is the state of the whole network. Although it is anybody's guess whether the participating molecules will be identified through biochemical purification, reverse genetics or by the further study of developmental mutants, plant development is now on a new track. The study of elements of signal transduction systems such as protein kinases might provide unifying principles to understand basic mechanisms of pattern formation.

\section{REFERENCES}

Baum DA (1998) The evolution of plant development. Curr. Opin. Plant Biol. 1:79-86.

Bowman JL, Eshed Y (2000) Formation and maintenance of the shoot apical meristem. Trends Plant Sci. 5:110-115.

Breton C, Faure JE, SDumas C (1995) From in vitro fertilization to early embryogenesis in maize. Protoplasma 187:3-12.

Clark SE, Running MP, Meyerowitz EM (1993) CLAVATA1, a regulator of meristem and flower development in Arabidopsis. Development 119:397-418.

Clark SE, Running MP, Meyerowitz EM (1995) CLAVATA3 is a regulator of shoot and floral meristem and flower development affecting the same processes as CLAVATA1. Development 121:2057-2067.

Clark SE, Williams RW, Meyerowitz EM (1997) The CLAVATA1 gene encodes a putative receptor kinase that controls shoot and floral meristem size in Arabidopsis. Cell $89: 575-585$.

Coen ES (1991) The role of homeotic genes in flower development and evolution. Annu. Rev. Plant Physiol. Plant Mol. Biol. 42:241-279.

Coen ES, Meyerowitz EM (1991) The war of whorls: genetic interactions controlling flower development. Nature 353:31-37.

Coen ES, Nugent JM, Luo D, Bradley D, Cubas P, Chadwick M, Copsey L, Carpenter R (1995) Evolution of floral symetry. Phil. Trans. R. Soc. Lond B 350:35-38.

Doebley J, Stec A, Hubbard L (1997) The evolution of apical dominance in maize. Nature 386:485-488.

Doerner P (1995) Radicle development. Curr. Biol. 5:110-112.

Dornelas MC (2000) Construindo Flores: O controle molecular da arquitetura floral. Biotecnologia 12:44-46

Dornelas MC, Van Lammeren AAM, Kreis M (2000) Arabidopsis thaliana SHAGGY-related protein kinases (AtSK11 and 12) function in perianth and gynoecium development. Plant J. 21:419-429.
Dornelas MC, Wittich PE, Von Recklinghausen IR, Van Lammeren AAM, Kreis M (1999) Characterization of three novel members of the Arabidopsis SHAGGY-related protein kinases (ASK) multigene family. Plant Mol. Biol. 39:137-147.

Dornelas MC, Lejeune B, Dron M, Kreis M (1998) The Arabidopsis Shaggy-related protein kinase (ASK) gene family: structure, organization and evolution. Gene 212:249-257.

Dornelas MC, Schwebel-Dugue N, Thomas M, Lecharny A, Kreis M (1997) Three New cDNAs Related to SGG/GSK3 (SHAGGY/Glycogen Synthase Kinase-3) from Arabidopsis thaliana. Plant Physiol. 113:306.

Duboule D, Wilkins AS (1998) The evolution of 'bricolage'. Trends Genet. 14:54-59.

Garcia-Bellido A (1996) Symetries through organic evolution. Proc. Natl. Acad. Sci. USA 93:14229-14232.

Gasser CS, Broadhvest J, Hauser BA (1998) Genetic analysis of ovule development. Annu. Rev. Plant Physiol. Plant Mol. Biol. 49:1-24.

Goff S.A. et al. (2002) A draft sequence of the rice genome (Oryza sativa L. ssp. japonica) Science 296:92-100.

Gould SJ, Eldredge N (1993) Punctuated equilibrium comes to age. Nature 366:223-227.

Gubb D (1998) Cellular polarity, mitotic synchrony and axes of symetry during growth. Where does the information come from? Int. J. Dev. Biol. 42:369-377.

Honma T, Goto K (2001) Complexes of MADS-box proteins are sufficient to convert leaves into floral organs. Nature 409:525-529.

Jürgens G, Grebe M, Steinmann T (1997) Establishment of cell polarity during early plant development. Curr. Opin. Cell Biol. 9:849-852.

Kenrick P, Crane PR (1997) The origin and early evolution of plants on land. Nature 389:33-39.

Kimble J (1994) An ancient molecular mechanism for establishing embryonic polarity? Science 266:577-580.

Kropf D (1997) Induction of polarity in fucoid zygotes. Plant Cell 9:1011-1020.

Kupiec JJ (1997) A Darwinian theory for the origin of cellular differentiation. Mol. Gen. Genet. 255:201-208.

Laufs P, Jonak C, Traas J (1998) Cells and domains: two views of the shoot meristem in Arabidopsis. Plant Physiol. Biochem. 36:33-45.

Laux T, Jürgens G (1997) Embryogenesis: a new start in life. Plant Cell 9:989-1000.

Lu P, Porat R, Nadeau J, O’Neill S (1996) Identification of a meristem L1 layer specific gene in Arabidopsis that is expressed during embryonic pattern formation and defines a new class of homeobox genes. Plant Cell 8:2155-2168. 
Luo D, Carpenter R, Vincent C, Copsey L, Coen E (1995) Origin of floral asymmetry in Antirrhinum. Nature 383:794-799.

Lewis EB (1978) A gene complex controlling segmentation in Drosophila. Nature 276:565-570.

Martin C, Bhatt K, Baumann K (2001) Shaping in plant cells. Curr. Opin. Plant Biol. 4:540-549.

Meyerowitz EM (1997) Genetic control of cell division patterns in developing plants. Cell 88:299-308.

Nüsslein-Volhard C, Wieschaus E. (1980) Mutations affecting segment number and polarity in Drosophila. Nature 287:795-801.

Palopoli MF, Patel NH (1996) Neo-Darwinian developmental evolution: can we bridge the gap between pattern and process? Curr. Opin. Genet. Dev. 6:502-508.

Rojo E, Sharma VK, Kovaleva V, Raikhel NV, Fletcher JC (2002) CLV3 is localized to the extracellular space, where it activates the Arabidopsis CLAVATA stem cell signaling pathway. Plant Cell 14:969-77.

Sachs T (1988) Epigenetic selection: an alternative mechanism of pattern formation. J. Theor. Biol. 134:547-559.

Sakai H, Medrano LJ, Meyerowitz EM (1995) Role of SUPERMAN in maintaining Arabidopsis floral whorl boundaries. Nature 378:199-203.

Schneitz K, Baker SC, Gasser CS, Redweik A (1998) Pattern formation and growth during floral organogenesis: HUELLENLOS and AINTEGUMENTA are required for the formation of the proximal region of the ovule primordium in Arabidopsis thaliana. Development 125:2555-2563.

Sessions A, Yanofsky MF, Weigel D. (1998) Patterning the floral meristem. Cell Dev. Biol. 9:221-226.

Siegfried E, Perkins LA, Capaci TM, Perrimon N (1990) Putative protein kinase product of the Drosophila segment polarity gene zeste-white-3. Nature 345:825-829.

Skaer H (1998) Who pulls the string to pattern cell division in Drosophila? Trends Gen. 14:337-339.
The Arabidopsis Genome Initiative (2000) Analysis of the genome sequence of flowering plant Arabidopsis thaliana. Nature 408:796-815.

Theissen G, Becker A, Di Rosa A, Kanno A, Kim JT, Münster T, Winter KU, Saedler H (2000) A short history of MADSbox genes in plants. Plant Mol. Biol. 42:115-149.

Turing A. (1936) On computable numbers, with an application to the Entscheidungsproblem, Proc. Lond. Mathem. Soc. 42:230-265.

Van Den Berg C, Willemsen V, Hage W, Weisbeek P, Scheres B (1995) Determination of cell fate in the Arabidopsis meristem by directional signaling. Nature 378:62-65.

Vincent CA, Carpenter R, Coen ES (1995) Cell lineage patterns and homeotic gene activity during flower development of Antirrhinum. Curr. Biol. 5:1449-1458.

Willemse MTM, Van Went JL (1984) The female gametophyte. In: Johri, BM (ed), Embryology of Angiosperms, pp.159196. Springer Verlag, New York.

Williams RW, Wilson JM, Meyerowitz EM (1997) A possible role for a kinase associated protein phosphatase in the Arabidopsis CLAVATA1 signalling pathway. Proc. Natl. Acad. Sci. USA 94:10468-10472.

Wilson I, Vogel J, Somerville S (1997) Signalling pathways: a common theme in plants and animals? Curr. Biol. 7:R175-R178.

Weigel D, Meyerowitz EM (1994) The ABCs of floral homeotic genes. Cell 78:203-209.

Wolpert L (1996) One hundred years of positional information. Trends Genet. 12:359-369.

Woodgett JR (1990) Molecular cloning and expression of glycogen synthase kinase-3/Factor A. EMBO J. 9:24312438.

Yu J. et al. (2002) A draft sequence of the rice genome (Oryza sativa L. spp. indica). Science 296:79-92. 